\title{
A pedagogia do ciclo da água urbano: formas de abordagem para promover cidades sensíveis à água
}

\author{
NOBREGA, Gabriel Dutra Ponte ${ }^{1}$ \\ ANDRADE, Liza Maria Souza de ${ }^{2}$ \\ LEMOS, Natália da Silva ${ }^{3}$ \\ 1Faculdade de Arquitetura e Urbanismo, Universidade de Brasília, Brasília Brasil.gabriel1996.dutra@gmail.com \\ ${ }^{2}$ Faculdade de Arquitetura e Urbanismo, Universidade de Brasília, Brasília Brasil. lizamsa@gmail.com \\ 3Faculdade de Arquitetura e Urbanismo, Universidade de Brasília, Brasília Brasil. Lemos.natalia@gmail.com
}

\begin{abstract}
Resumo
Este trabalho apresenta pedagogias da água para conscientização da importância do ciclo da água urbano que contribuem na construção do "Manual pedagógico do ciclo da água urbano com padrões de infraestrutura ecológica para promover o engajamento social frente à escassez hídrica" inserido no projeto Brasília Sensível à Água. Como fundamentos, adota alguns projetos pedagógicos existentes, relacionados com a promoção de cidades sensíveis à água e os produtos de pesquisas anteriores do projeto Brasília Sensível à Água, que abordaram padrões espaciais e técnicas de infraestrutura ecológica (ProlC 2014/2015, ProlC 2015/2016 e ProlC 2016/2017), atentos às novas formas de ocupações urbanas ou reabilitação de áreas integradas ao restabelecimento do ciclo da água urbano. Os estudos focam o livro "Água como matriz ecopedagógica: um projeto a muitas mãos" de Catalão e Socorro (2006), a página no Facebook chamada "Água, sua linda", administrada pela Aliança pela Água, o programa australiano Cidades Sensíveis à Água e o evento ocorrido dentro do FAMA organizado pelo grupo de pesquisa Água e Ambiente Construído - FAU/UnB. Este trabalho obteve o prêmio de Melhor Trabalho na Área de Artes e Humanidades do $24^{\circ}$ Congresso de Iniciação Científica da UnB e do $15^{\circ}$ Congresso de Iniciação Científica do DF, ambos em 2018.
\end{abstract}

Palavras-Chave: Cidades Sensíveis a Águas, Ciclo da Água Urbano, Pedagogia das Águas, Ecopedagogia, Hidroalfabetização, Manual pedagógico do ciclo da água urbano.

\begin{abstract}
Paper propounds water pedagogies to raise awareness the importance of the urban water cycle that contribute to build up the "Manual pedagógico do ciclo da água urbano com padrões de infraestrutura ecológica para promover o engajamento social frente à escassez hídrica" worked in "Projeto Brasília Sensivel à Água". As foundation, adopts some existing pedagogical projects correlated to the foment of water sensitive cities and the results of previous researches of "Projeto Brasília Sensível à Águra", wich broached spatial patterns and technical of ecological infrastructure (ProlC 2014/2015, ProlC 2015/2016 and ProlC 2016/2017), conscious to new form of urban occupancy or rehabilitation of areas embedded with the reinstatement of urban water cycle. The studies concentrate on the book "Água como matriz ecopedagógica: um projeto a muitas mãos" by Catalão and Socorro (2006), the Facebook page called "Água, sua linda", administered by the Water Alliance, the Australian Water Sensitive Cities program and the event held within the FAMA organized by the "Grupo de Pesquisa Água e Ambiente Construído" - FAU / UnB. The paper highlighted as Best Work in the Arts and Humanities Area of the "24 Congresso de Iniciação Científica da UnB e do $15^{\circ}$ Congresso de Iniciação Científica do DF", both in 2018.
\end{abstract}

Key-Words: Water sensitive city, Urban water cycle, Water pedagogy, Eco pedagogy, Hidro literacy, Urban water cycle teaching manual 


\section{Introdução}

$\mathrm{Na}$ temática do ciclo da água urbano que envolve a configuração de relações existente no espaço urbano e demandas por aplicação de padrões de infraestrutura ecológica, o trabalho visa contribuir com estudos sobre cidades sensíveis à água pela abordagem da pedagogia do ciclo da água urbano, que consiste na hidroalfabetização dos cidadãos. No campo da Arquitetura e do Urbanismo, essa pedagogia vem sendo trabalhada no projeto Brasília Sensível à Água do Grupo Água e Ambiente construído (AAC/FAU/UnB), sobre o qual se insere os estudos de técnicas da infraestrutura ecológica mediante a situação das águas, água potável, água da chuva, água residual, no Distrito Federal e suas respectivas relações com as mudanças climáticas e o Bioma Cerrado.

Os estudos são estabelecidos por uma relação direta entre tecnologia e sociedade com a demanda por novas redes de abastecimento e tratamento de águas, como redes distribuídas de entrada e saída, considerando o ecosaneamento, a infraestrutura ecológica, a agroecologia nas ocupações existentes e novas expansões para promover o restabelecimento do ciclo da água urbano. Compreende a visão global do ambiente construído e a relação com os ecossistemas da paisagem visando a conscientização e entendimento do processo de formação cidadã, relacionado as necessidade de recuperação dos ciclos da água urbano sobre a bacia hidrográfica.

É necessária uma visão mais ampliada e sistêmica dos problemas, uma análise do processo total e a longo prazo. A dinâmica urbana conduz as pessoas à desvalorização e a não compreensão do princípio e do fim do "ouro azul". Considera-se apenas que o problema hídrico é da administração pública. O ideal é que superemos a "hidroalienação" causada pelo "hidroanalfabetismo", temos que buscar novas abordagens pedagógicas, informar os problemas e gerar sentimento de corresponsabilidade na gestão e busca de soluções. (CATALÃO, 2006; RIBEIRO, sd).

No processo de "hidroalfabetização" esclarecer a diferença entre o ciclo convencional e o ciclo urbano da água é crucial. Mais do que evaporações e precipitações, que abastecem os rios e as redes subterrâneas, o segundo modelo envolve fatores que o tornam mais complexo que o primeiro. Analisar - ciclo da água urbano é considerar as alterações da paisagem realizadas pelo homem: impermeabilização do solo, canalização de corpos hídricos, telhados, calhas, sistemas de esgoto, tratamento de água, irrigação na agricultura, tanques subterrâneos, hidrelétricas, represas, todas essas intervenções alteram o ciclo hidrológico, que passa a ser uma cadeia mais complexa com diversas variáveis.

A "hidroalfabetização" começa pelo entendimento de que água é um recurso intrínseco à vida. Todas as espécies estão imersas nos processos e fluxos naturais nos quais a água é fundamental. Tales de Mileto, filósofo grego (624 a.C.-558 a.C.) já pensava a água como "arché", que seria um elemento constituinte de todas as coisas e relacionado à existência. $\mathrm{O}$ corpo humano saudável é constituído de mais de $60 \%$ de água, então desde sua constituição celular o homem depende do recurso hídrico que supera o interior alcançando comportamentos externos e relações sociais.

Se analisada a trajetória da civilização humana, observa-se que desde o princípio a água é fator determinante para a instalação e desenvolvimento de uma cultura, por exemplo as sociedades mesopotâmicas delimitadas pelos Rios Tigre e Eufrates e o Egito, banhado pelo Rio Nilo. Nesse contexto urbano, os cursos hídricos assumem, além de seus papéis naturais, importância política e econômica, fomentando tecnologias que geram recursos de manipulação e controle desse bem, o que é evidenciado desde Roma, com os aquedutos que permitiam um centro urbano distante da fonte aquática, até atualmente, quando os chineses lançaram na atmosfera projéteis com iodeto de prata para acelerar as chuvas e evitar precipitações durante a abertura das Olimpíadas em 2008, o que reflete o pensamento do homem contemporâneo quanto ao controle e a dominação da natureza e suas forças (HERZOG, 2013). 
No âmbito do planejamento urbano, segundo Gehl (2013), as estruturas e o planejamento influenciam o comportamento do indivíduo e o funcionamento da própria cidade. A congruência das estruturas e da dinâmica urbana colocam a natureza como segundo plano, desconectada dos processos e padrões espaciais. Andrade (2014) acredita que essa ruptura causa impacto no equilíbrio dos ecossistemas, da paisagem, da bacia hidrográfica e no ciclo hidrológico, refletindo diretamente na qualidade de vida dos cidadãos por influência das atividades humanas e forma urbana, o que para Herzog (2013) é configurado como importante indicador do funcionamento das cidades.

As cidades não param de crescer, a expectativa é que em 2050, a população mundial chegará a 9 milhões de pessoas, desse montante, um número estimado de 6,3 bilhões de pessoas habitará as cidades do planeta. Em uma pesquisa realizada pela Organização das Nações Unidas, a ONU, em 2014, das 500 maiores cidades do mundo, uma em cada quatro cidades já está em situação de "estresse hídrico" (quantitativo ou qualitativo) quando o abastecimento anual fica abaixo dos $1,7 \mathrm{mil} \mathrm{m}^{3}$ por pessoa. De acordo com projeções, a demanda por água doce vai superar o abastecimento em $40 \%$, em 2030.

As causas do estresse hídrico ou da crise hídrica nas cidades estão relacionadas a vários fatores interligados, entre eles: (a) o desequilíbrio na ocupação das populações nos territórios com baixa oferta de água; (b) o desmatamento na bacia hidrográfica reduzindo a infiltração da água no solo e a recarga de aquífero; (c) alterações climáticas que incidem na quantidade de formação de chuva na região, com menores taxas pluviométricas verificadas nos últimos anos; (d) a má gestão da demanda de água que inclui a falta de garantia na oferta e investimento público em áreas mais pobres periféricas, em áreas periurbanas e no campo; (e) poluição e assoreamento dos rios, córregos e lagos, seja pelo uso intensivo de produtos químicos em atividades industriais ou rurais, ausência de tratamento de esgoto, uso de tecnologias ultrapassadas de saneamento ambiental bem como a falta de tratamento das águas de drenagem urbana.

O Brasil possui $12 \%$ dos recursos hídricos do planeta, $3 \%$ da população mundial e $6 \%$ do território mundial. São valores consideráveis de bens, terra e indivíduos integrados, se comparados com a Índia que é duas vezes e meia menor do que o Brasil e tem uma população quase seis vezes maior. Ribeiro (sd) coloca que a necessidade nos dois países é semelhante, o que muda são os sistemas de gestão das águas. Mesmo com todo aparato legislativo, como a criação da ANA (Agência Nacional das Águas) em 2000 e todos os comitês de bacias e estratégias, no que diz respeito à política e gestão da água, o Brasil apresenta problemas sérios de crise hídrica, evidenciados em São Paulo e no Distrito Federal, respectivamente nos anos de 2009 e 2016.

Para verificar a situação da água no Brasil, a Agência Nacional de Água, a ANA, lançou o relatório "Conjuntura dos Recursos Hídricos Brasil 2017" http://conjuntura.ana.gov.br/ onde é possível verificar e caracterizar a crise da água nas regiões brasileiras e sua espacialização e evolução no tempo, pois os fatores meteorológicos, hidrológicos, demográficos, institucionais e o desmatamento, entre outros, que levam à crise são, em geral, os mesmos.

No caso Distrito Federal, com o agravamento do desmatamento do Cerrado pelo agronegócio, além da redução do volume de precipitação e a elevação da temperatura, os principais reservatórios apresentam suas vazões naturais reduzidas e taxas de evaporação aumentadas. Nos últimos 16 anos, não houve um planejamento e execução de obras estruturantes, sistemas de esgotamento sanitário e de drenagem ultrapassados, mesmo com o crescimento da população contínuo, segundo o IBGE na ordem de 60 mil por ano em média. Isto fez com que o abastecimento de água ficasse comprometido, impondo, assim, o racionamento de água no início de 2017, em plena estação chuvosa. No entanto, a solução para a crise e uma reversão do cenário não estão apenas relacionadas a medidas de racionamento, que podem até gerar uma mobilização rápida e resultado imediato. 
A pouca atenção à causa hídrica reflete na educação atual a respeito do ciclo da água, que é abordado e discutido nas escolas, mas de maneira suficiente. A solução para a crise e uma reversão do cenário, não está apenas nas medidas de racionamento, que geram uma mobilização rápida e resultado imediato, sem efetividade de análise do processo total e a longo prazo. $O$ ideal é que superemos a "hidroalienação" causada pelo "hidroanalfabetismo" (RIBEIRO, sd). A dinâmica urbana conduz as pessoas à desvalorização e a não compreensão do princípio e do fim do recurso, sendo argumentado que o problema hídrico é da administração pública. De acordo com Ribeiro (sd), a "hidroalienação" se dissolve em crises de falta de água ou problemas com água em abundância, rebatendo no paradoxo do Brasil ter muitos recursos e, mesmo assim, sofrer crises de abastecimento.

Analisar abordagens pedagógicas vinculadas a contextos locais, conforme Catalão e Jacobi (2010), surge da necessidade de informar os problemas e gerar sentimento de corresponsabilidade na gestão e busca de soluções. Promover essa educação, para Ribeiro (sd) é investir em "hidroalfabetização" e "hidroconsciência", desde informação aos governantes, a quem cabe a responsabilidade de formular políticas e programas que levem o conhecimento à sociedade, até aos comunicadores, professores, universitários e todos que, de alguma forma, também colaboram com o aprendizado. $O$ objetivo é gerar uma conscientização coletiva, alcançando todas as áreas do conhecimento. A partir dessa conexão de todos os departamentos educadores, com uma base de qualidade, o resultado é um foco coletivo na questão da água, como proposto por Andrade (2014).

No processo de "hidroalfabetização" esclarecer a diferença entre o ciclo convencional e o ciclo urbano da água é crucial. Mais do que evaporações e precipitações, que abastecem os rios e as redes subterrâneas, o segundo modelo envolve fatores que o tornam mais complexo que o primeiro. Analisar o ciclo da água urbano é considerar as alterações da paisagem realizadas pelo homem: impermeabilização do solo, canalização de corpos hídricos, telhados, calhas, sistemas de esgoto, tratamento de água, irrigação na agricultura, tanques subterrâneos, hidrelétricas, represas, todas essas intervenções alteram o ciclo hidrológico, que passa a ser uma cadeia mais complexa com diversas variáveis.

Uma das direções importantes é ilustrar com bons exemplos, o que motiva o cidadão e aproxima o assunto, antes teórico, da prática, que termina por gerar toda a mudança. O programa do governo australiano "Desenho Urbano Sensível à Água" (Water Sensitive Urban Design - WSUD) considera as configurações de intervenção humana nos processos hídricos, assegurando valorização da paisagem urbana no projeto, minimizando impactos sobre o ciclo da água. Além de planejamento urbano com gestão, proteção e conservação do ciclo urbano da água, existe uma estratégia nacional de gestão da qualidade da água que habilita empreendimentos para alcançar localmente a qualidade da água. São políticas e diretrizes que consideram abastecimento e manejo de águas provenientes da chuva e dos esgotos, com preocupações para com as águas potáveis, de precipitação e residuais, desde estradas até os maiores edifícios.

A pesquisa "A pedagogia do ciclo da água urbano: novas formas de abordagem para promover cidades sensíveis à água" pretende prosseguir com estudos sobre novas pedagogias e linguagens que aproximem a população do tema (compreendendo que a promoção da cidade sensível depende do entendimento do cidadão) e gerando um produto de embasamento para um manual pedagógico sobre o ciclo da água urbano, possibilitando engajamento social frente à escassez hídrica local.

No contexto da bacia hidrográfica, o ciclo da água urbano, apesar de sua complexidade, fornece bases sólidas para estudar o balanço hídrico e a condução de estoques de água de áreas urbanas, captação, tratamento, desenvolvimento ou situação local. Demonstra as conexões necessárias e interdependência dos recursos da água urbana e atividades humanas por meio de uma gestão integrada evocando o desenvolvimento de novas abordagens pedagógicas vinculadas a contextos 
locais e que sejam apropriadas às comunidades visto que os problemas são próprios de cada lugar.

\section{Metodologia da pesquisa Pedagogia do Ciclo da Água Urbano}

A gestão "total do ciclo hidrológico" no meio urbano tem como objetivo reduzir o consumo de água potável, maximizar a água de reuso, reduzir a descarga de águas residuais, minimizar a poluição de águas pluviais antes de serem despejadas no ambiente aquático e maximizar a proteção das águas subterrâneas. O urbanismo baseado nos fluxos de água, com o desenho de cidades em torno do papel e da dinâmica da água, tem-se tornado uma ferramenta poderosa em muitas partes do mundo desenvolvido. $O$ desenho urbano com foco na questão da água deve ser uma consequência da ocupação ecologicamente sustentável, segundo o programa do governo australiano WSUD (Water Sensitive Urban Design) para "Cidades Sensíveis à Água".

A gestão da água dentro do ambiente construído requer uma implementação e avaliação de ações que promovam a preservação de recursos hídricos com justiça social e ambiental bem como compreender o que seja uma ocupação ecologicamente sustentável, abrangendo o contexto socioeconômico do planejamento do uso do solo (incluindo a questão cultural das comunidades). Significa integrar políticas e planejamento do uso do solo e preservação ambiental, transporte, energia, dinâmica da população e seus resíduos e com a gestão, proteção e conservação do ciclo urbano da água que fazem parte da infraestrutura ecológica do saneamento. Isto garante a gestão da água urbana ou "governança", sensível aos ciclos hidrológicos e ecológicos naturais.

As pesquisas tiveram como base o trabalho de Andrade (2014) que propõe uma metodologia para promover o desenho urbano sensível à água baseada em padrões espaciais dos ecossistemas urbanos, fundamentada em "uma linguagem de padrões" de Alexander et. al (1977) que sistematizou 253 padrões de vilas, bairros, habitações, jardins, etc., seguindo a lógica de uma escala maior para uma menor, viabilizando conexões entre eles, considerando contexto, problema e solução. Andrade (2014) apresenta uma síntese com 38 padrões, aplicados no desenho urbano sensível à água e fundamentados nos documentos de infraestrutura ecológica, eco saneamento, agricultura e permacultura. A intenção é estimular o pensamento sistêmico e transdisciplinar para gerar um produto acessível à sociedade.

Para a pesquisa sobre a Pedagogia do Ciclo da Água Urbano foi desenvolvida uma análise de projetos pedagógicos existentes e suas relações com a intenção de promover cidades sensíveis à água, apoiando-se também nos produtos gerados por pesquisas anteriores, que abordaram padrões espaciais e técnicas de infraestrutura ecológica (ProlC 2014/2015, ProlC 2015/2016 e ProlC 2016/2017).

A diversidade de propostas analisadas variou desde o livro "Água como matriz ecopedagógica: um projeto a muitas mãos" de Vera Catalão e Maria do Socorro (2006), que apresenta um compilado de autores retratando experiências educativas, até uma página no Facebook chamada "Água, sua linda", administrada pela Aliança pela Água com apoio da ONG Bem-Te-Vi, que tem por objetivo disponibilizar informações claras e acessíveis para todos.

Também foi analisado o programa do governo australiano "Desenho Urbano Sensível à Água" (Water Sensitive Urban Design - WSUD), como resposta à Seca do Milênio, uma crise hídrica que ocorreu em todo o país. O momento político pelo qual o Brasil está passando é oportuno para reflexões e análises sobre os aprimoramentos necessários e desafios a serem superados, especialmente em situação de crise hídrica em várias regiões do país.

Por último, as considerações apresentadas no "FAMA - Fórum Alternativo Mundial da Água", movimento alternativo que questionou a legitimidade do Fórum Mundial da Água, promovendo diversas discussões, palestras e trabalhos acerca do direito à água e outras questões que envolvem o recurso 
hídrico, que colaborou com a pesquisa por meio de oficinas na Faculdade de Arquitetura e Urbanismo no formato de Seminário, no contexto do projeto Brasília Sensível à Água do Grupo de Pesquisa Água e Ambiente Construído.

\section{Da Pedagogia da Água à Pedagogia do Ciclo da Água Urbano}

\section{1. Água como matriz pedagógica}

Os elementos O projeto "Água como matriz ecopedagógica: um projeto a muitas mãos", trata de uma articulação entre a Universidade e três escolas próximas a cursos hídricos no Distrito Federal. O livro agrega textos que relacionam diversas áreas e projetos correlacionados com o ponto da multidisciplinaridade sugerido por Andrade (2014). O objetivo é a sensibilização e conscientização do cidadão por meio de atividades e pesquisas, além de elaborar materiais didáticos que aproximem as experiências teóricas no cotidiano da escola. Para isso foram realizados cursos embasados na transdisciplinaridade, a fim de formar os professores nessa missão de transformar culturas pela prática social.

A transversalidade é o primeiro aspecto pedagógico considerado como princípio pedagógico proposto pelo projeto de Catalão (2006), vinculado a metodologia de pesquisa-ação. Trata-se de um conceito visto em Hugon e Seibel (1988, apud Catalão, 2006), que é desenvolvido em espiral, mantendo como constante o duplo objetivo de transformar a realidade e de produzir conhecimentos compartilhados sobre essas transformações.

Essa pedagogia busca resgatar a ligação entre o observador e o objeto de estudo, que agrega à pesquisa a subjetividade dos envolvidos. É premissa dessa pedagogia, o conhecimento produzido em reflexões sobre atitudes de mudança, sendo adicionado ao processo a observação do próprio ato humano, estimulante da renovação de práticas e problematizado por situações indutoras das mudanças. De acordo com Gaston Pineau, citado em Catalão (2006), a pesquisa-ação é um processo de autoformação, heteroformação e ecoformação, englobando relações individuais, com o grupo e com o meio.

Catalão (2006) apresenta quatro temáticas a partir de Renè Barbier, elas tratam da identificação do problema e a contratualização, do planejamento e da realização em espiral, das técnicas de pesquisaação e da teorização, avaliação e publicação de resultados. O primeiro passo é tomado pelo grupo de indivíduos envolvidos com o objeto, que identifica o problema e declara intenção de mudanças para solucioná-lo. O segundo passo compreende as práticas e vivências do grupo para obter dispositivos de pesquisa. As técnicas podem ser diversas, Catalão (2006) cita o diário de itinerância, produto que expõe a movimentação do grupo para alcançar o objetivo, e por último as análises e avaliações dos resultados, que que gera o processo espiral de avaliar a ação, gerar uma teoria que embasa a próxima ação que também será analisada posteriormente.

A transdisciplinaridade é o meio evidente por não lidar com a separação de disciplinas. O objeto de estudo consiste numa rede múltipla inter-relacionada, que permite abordar o conteúdo por formatações desde atividades de trabalho corporal, motivações teóricas e expositivas, debates, até apropriação de problemas para a prática: vivenciá-los, refletir em grupo e seguir o processo em espiral.

$\mathrm{Na}$ avaliação final, nos depoimentos dos participantes são recorrentes a valorização da transversalidade, que abrange os temas de maneira mais completa, as mudanças de pensamentos e atitudes, que se deram como consequência do processo, além disso, muitos relatos expressam a importância dos trabalhos corporais propostos, que aproximam o indivíduo do seu papel de participante do ecossistema, facilitando a observação do pesquisador/pesquisado inserido no meio. 


\section{2. Água, sua linda}

A Aliança pela Água é uma coalizão criada em 2014, em São Paulo, motivados pela crise da água na metrópole, composta por mais de 60 organizações e movimentos de diversas áreas preocupados com a causa hídrica. Acreditam que o recurso não é uma mercadoria, que todos os níveis de governo têm responsabilidade no assunto e promovem a recuperação e reposição de fontes de água existentes. Os princípios são: cuidar, reduzir, tratar, reutilizar e transparência. Atuam pela construção de uma "Nova Cultura de Cuidado com a Água" por diversos meios, como o projeto "Água, sua linda" com apoio da ONG Bem-Te-Vi.

Esse projeto questiona os internautas a respeito de assuntos referentes à água. Por meio de redes sociais como Facebook, Tumblr e Twitter divulgam informações com linguagem acessível através de infográficos e ilustrações. Atualmente, são mais de 145 mil seguidores no Facebook e já publicaram mais de 500 ilustrações informativas, que embora variem em função da interação do público, atingem bons resultados como a Figura 1 que mostra a situação das mineradoras envolvidas no escândalo do Rio Doce. Essa publicação obteve mais de 6,6 mil curtidas, 39 mil compartilhamentos e cerca de 790 comentários.

Nessa pesquisa foram levantadas todas as 531 imagens publicadas, com a finalidade de análise de assuntos, formas de abordagem e possíveis colaborações para o desenvolvimento do Manual Pedagógico. Foram observadas mudanças de identidade visual ao longo dos anos, o que revela preocupação estética com a linguagem usada nas redes sociais, sendo o design atual influenciado pelas tendências de Flat Design, que se baseia no uso de elementos mais puros, cores menos saturadas, poucas variações de profundidade e clareza nas informações, em favor da funcionalidade.

Os temas foram sistematizados em 7 pastas. São elas: bons exemplos (73 imagens), maus exemplos (160 imagens), casos no Brasil (68 imagens), ciclo da água (21 imagens), curiosidades (151 imagens), datas comemorativas (29 imagens) e doenças (20 imagens). A pasta "bons exemplos" tratou temas desde ações emergenciais de curto prazo para redução de consumo até dicas de como fazer uma cisterna, são imagens que mostram ações, sistemas construtivos, decisões políticas, reformas, que priorizam a questão hídrica (Figura 1, imagem ao centro). Já na pasta "maus exemplos" os casos inversos, de fatos que não valorizaram a água como deveriam (Figura 1, imagem à direita). Na pasta "casos no Brasil" são apresentados gráficos, mapas e informações mais direcionadas à realidade das cidades e à situação nacional (Figura 1, imagem à esquerda).

Figura 1. Gráficos, informações e mapas mais direcionadas à realidade das cidades e à situação nacional.
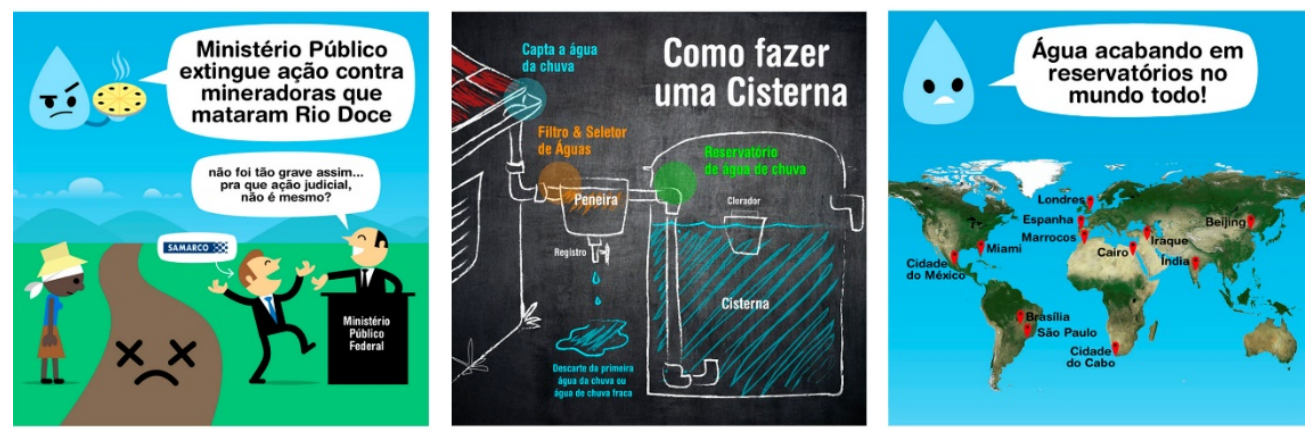

Fonte: Gabriel Nóbrega, disponível em < https://www.facebook.com/aguasualinda >, acessado em jul. 2018.

Pela pasta "ciclo da água" constatou-se relevância por informar respeito do ciclo da água urbano (Figura 2, imagem à esquerda). Quanto a pasta "curiosidades" foram levantadas informações indiretamente ligadas à água: quanto se gasta para se obter meio quilo de carne, quanto uma galinha consome para produzir um ovo (Figura 2, imagem ao centro esquerdo). A pasta "datas comemorativas" (Figura 2, imagem ao centro direito) abordou atenção a datas importantes como Dia Mundial da Água, 
Dia do Meio Ambiente, festas de fim de ano. Por fim, a pasta "doenças" abordou as publicações de temas como dengue, hepatite, febre amarela (Figura 2, imagem à direita).

Figura 2. Infográficos sobre o ciclo da água.
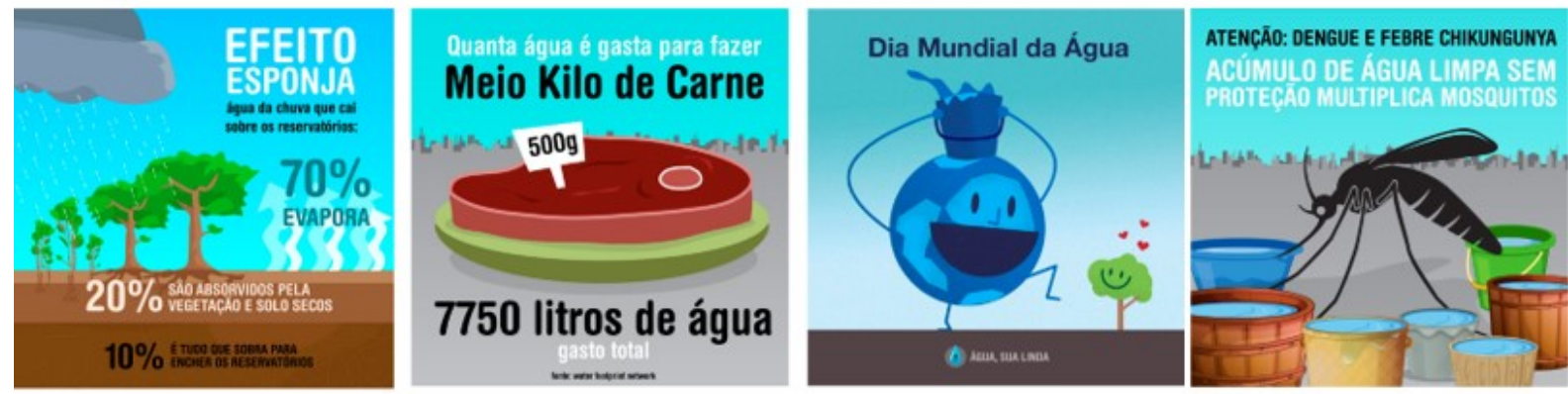

Fonte: Gabriel Nóbrega, disponível em < https://www.facebook.com/aguasualinda >, acessado em jul. 2018.

Jonah Berger, professor de psicologia de Harvard, aponta "seis princípios do contágio", seis passos que podem criar um conteúdo provável a se espalhar, se difundindo boca a boca até influenciar o agir do indivíduo na sociedade. São eles: moeda social, gatilhos, emoção, público, valor prático e histórias, detalhados na Tabela 1.

Tabela 1: Os seis princípios de contágio de Jonah Berger.

\begin{tabular}{ll}
\hline $\begin{array}{l}\text { Moeda } \\
\text { social }\end{array}$ & $\begin{array}{l}\text { É o status visível que uma publicação pode representar a respeito de quem a pública. No "Água, sua } \\
\text { linda", a moeda seria a demonstração de interesse nas causas ambientais, visto que o assunto } \\
\text { sustentabilidade é recorrente na atualidade. }\end{array}$ \\
Gatilho & $\begin{array}{l}\text { São os estímulos de assuntos periféricos gerados pela abordagem de um principal, o que a página } \\
\text { "Água, sua linda" atinge ao tratar de assuntos do próprio cotidiano do público alvo, por exemplo, } \\
\text { falando de desperdício faz lembrar a importância do uso consciente. }\end{array}$ \\
Emoções & $\begin{array}{l}\text { São as reações causadas no público, fortes emoções geram mais compartilhamentos, como quando } \\
\text { o objeto estudado informa que para se obter meio quilo de carne são gastos mais de } 7,5 \text { mil litros } \\
\text { d'água (Figura 5). A reação de espanto leva a pessoa a querer que as outras também acessem essa }\end{array}$ \\
informação. & $\begin{array}{l}\text { Envolve a legibilidade das informações, o que o projeto também acerta ao optar pelo Flat Design. } \\
\text { Público }\end{array}$ \\
Valor & $\begin{array}{l}\text { Como a informação publicada interfere diretamente na vida do receptor, no caso da intenção do } \\
\text { objeto estudado, beneficiando a saúde e o meio ambiente ao preservar os recursos hídricos. }\end{array}$ \\
Histórias & $\begin{array}{l}\text { Contextualizam os assuntos e possibilitam lidar com eles de maneira lúdica, princípio explorado em } \\
\text { posts relacionados ao ciclo da água, por exemplo. }\end{array}$ \\
\hline
\end{tabular}
Fonte: Gabriel Nóbrega.

\subsection{Water Sensitive Urban Design - WSUD}

Durante o período de crise hídrica grave, conhecido como a Seca do Milênio, o governo australiano criou um programa para promover cidades sensíveis à água: Water Sensitive Urban Design - WSUD (Desenho Urbano Sensível à Água), os resultados foram muito positivos e ele se tornou referência mundial no assunto. O programa atenta ao fato do ciclo da água ser diferente em regiões urbanas e compromete em projetar a paisagem para gerenciar fluxos e reciclar a água, através de recursos como: valas vegetadas, bacias de infiltração, sistemas de biorretenção ou bioinfiltração, alagados construídos, bacias de detenção ou retenção e telhados verdes, segundo Nunes (2011) e Melborne Water (2014) apud Huergo (2018, p.49).

O fornecimento de água nos centros urbanos foi diferente por todo a Austrália, em consequência da Seca do Milênio mediante as diferenças climáticas, os sistemas de fornecimento de água e das respostas pela criação de políticas públicas. As experiencias também se diferencia quanto ao público atingido. As respostas à seca grave requerem opções no campo da oferta e no campo da demanda pelos recursos hídricos, sobre as quais é primordial dar prioridade a opções de custo-benefício (custo mais baixo por volume) viável. Os programas sólidos de demanda incentivam e promovem a economia de água por parte de todos os usuários e públicos interessados (residências, negócios, indústrias e 
governos. No campo da oferta, a estratégia eficiente são as opções tecnológicas modulares, escaláveis, diversas e inovadoras.

Como princípios necessários para um bom resultado do projeto, a educação da população a respeito desses novos sistemas se deu a partir de guias, como os lançados pelo estado de Western Australia em 1994 e o guia do governo de Gold Coast, de 2005. As cidades foram desenvolvendo suas próprias políticas, e o manual da cidade de Adelaide, por exemplo, apresenta exemplos de métodos construtivos, orçamentos, legislações, manutenção, para diferentes escalas na cidade (HUERGO, 2018).

Além da estrutura teórica eficiente, a preocupação de educar o cidadão, não apenas pela importância, mas ainda pela parte técnica e específica das intervenções, concretizaram o projeto na prática. Também colaborou com o desempenho a flexibilização permitida e incentivada entre as cidades, visto que cada uma apresenta uma realidade e cultura individual. Huergo (2018) cita a organização do governo com relação ao financeiro, na qual o argumento é que mesmo a prática do Desenho Sensível não sendo a mais rentável, o governo substituiu intervenções no lote do proprietário com seu próprio dinheiro, por outras estratégias de porte maior dentro do município.

A seca representou tanto uma crise quanto uma oportunidade para inovação ao implatar novas iniciativas de economia de água e de incentivos em larga escala, e para potencializar a vontade política e da comunidade na realização de mudanças regulatórias e políticas necessárias.

O programa do governo australiano para "Cidades Sensíveis à água" (WSUD, 2013) enfatiza a questão da influência das configurações urbanas, os padrões espaciais, sobre os fluxos de recursos. Visa assegurar que o desenvolvimento urbano e a paisagem urbana sejam cuidadosamente projetados, construídos e mantidos de modo a minimizar os impactos sobre o ciclo da água urbano. É uma tentativa de aplicar as técnicas de infraestrutura verde e princípios de design responsivo ao clima, à segurança da água, à proteção contra cheias e à saúde ecológica das paisagens terrestre e aquática, desde o nível de toda a bacia ao nível da rua.

\subsection{O projeto Brasília Sensível à Água e os padrões espaciais}

O desmatamento do Bioma Cerrado no território e na fronteira do agronegócio, plantações de soja, milho e algodão, com o Estado de Goiás, no "Berço das Águas, comprometem ainda mais a situação do ciclo da água na região. Considerando o ciclo da água, o trinômio solo-vegetação-atmosfera, apesar de Brasília ser uma "cidade-parque", há uma excessiva impermeabilização do solo com o modelo urbano disperso que alteram os fluxos de água nas bacias hidrográficas, soluções ultrapassadas para a drenagem das águas pluviais causando assoreamento dos corpos d'água, tratamento de efluentes sanitários com alta produção de lodo efluente, consumo elevado de água acima da média nacional e, ainda, um aumento crescente da população, o que evidencia a necessidade de políticas públicas e ações integradas para promover a ocupação urbana ecologicamente sustentável.

Os parâmetros urbanísticos ou padrões espaciais urbanos devem estar em harmonia com outras políticas e planejamento do uso do solo e preservação ambiental, transporte, energia, dinâmica da população e seus resíduos e atender aos princípios de sustentabilidade em várias dimensões: social, econômica, cultural e ambiental.

O projeto "Brasília Sensível à Água" tratou de estudos sobre as águas no Distrito Federal considerando as mudanças climáticas e o Bioma Cerrado. Foram elaborados padrões espaciais e técnicas de infraestrutura ecológica e agroecologia, para futuras ocupações urbanas e restabelecimento do ciclo da água urbano na Bacia do Paranoá. A primeira fase do projeto teve como meta conectar estudos de outras áreas do conhecimento sobre a situação das águas no DF, cruzando dados e informações para então, a partir da problemática gerar novos padrões de desenho urbano sensível á água incluindo o 
trinômio solo-vegetação-atmosfera para captação, armazenamento de água, infiltração e evapotranspiração, tratamento de esgoto, bem como a produção de alimentos e saúde ambiental. A análise do problema foi direcionada especificamente para o território do Distrito Federal que contou com 5 pesquisas interligadas: (1) alterações climáticas e situação das águas, demandas por novos padrões de abastecimento de água; (2) o ciclo da água no cerrado: novos padrões urbanos para reestabelecer o equilíbrio do trinômio solo-vegetação- atmosfera; (3) hortas urbanas e jardins agroflorestais e a demanda por produção de alimentos na cidade para otimizar o uso de água; (4) novos padrões urbanos de saneamento ecológico, alguns casos bem sucedidos no DF e a relação com a saúde ambiental; (5) drenagem natural: novas demandas por infraestrutura ecológica frente ao futuro incerto de escassez de água

A pesquisa foi fundamentada nos estudos do WSUD (2013) da Austrália e da US-EPA (2006). O programa WSUD reconhece que todos os fluxos de água no ciclo da água urbano são um recurso: a água potável, a água da chuva, as águas de drenagem, os cursos d'água potável, águas cinza (água das pias de banheiro, chuveiro e lavanderia), águas negras (banheiro e cozinha) e as águas subterrâneas (mineralização de água). Após a identificação do problema em cada tema estudado, os padrões serão sistematizados no formato de "padrões de desenho" baseado em Alexander et al (1977) e Andrade (2014) "Contexto - Recomendação - Ilustração" que são interligados de maneira sistêmica. O método consiste em detalhar esses padrões espaciais, cada pesquisador com seu tema específico, mas utilizando uma linguagem mais apropriada à sociedade na forma de cartilha. Além desses padrões que serão apresentados, já forma sistematizados 75 padrões ilustrados. Adotou-se uma visão mais abrangente e sistêmica sobre Cidades Sensíveis à Água, fundamentada nos estudos do Water Sensitive Urban Design - WSUD (2013) da Austrália e da Environment Protect Agency US-EPA (2006) e de Andrade (2014). A Tabela 2 ilustra alguns dos padrões de infraestrutura ecológica que foram sistematizados.

Tabela 2: Exemplos dos padrões de infraestrutura ecológica do projeto Brasília Sensível à Água.

\begin{tabular}{|c|c|c|}
\hline \multicolumn{3}{|c|}{ PADRÕES DE INFRAESTRUTURA ECOLÓGICA } \\
\hline & Hortas urbanas e jardins agrof & restais \\
\hline Padrão & Problema/Contexto & Recomendação \\
\hline $\begin{array}{l}\text { Plantio Paisagístico } \\
\text { Produtivo }\end{array}$ & $\begin{array}{l}\text { Grandes áreas gramadas com } \\
\text { árvores isoladas e vastas } \\
\text { porções de solo exposto, e a } \\
\text { consequente compactação e } \\
\text { baixa infiltração de água. }\end{array}$ & $\begin{array}{l}\text { Forme núcleos de vegetação ao } \\
\text { redor das árvores já existentes no } \\
\text { local, usando da sucessão } \\
\text { ecológica para estruturar seu } \\
\text { plantio, se atendando a altura dos } \\
\text { extratos vegetais. }\end{array}$ \\
\hline $\begin{array}{l}\text { Reflorestamento e } \\
\text { Compensação Ambiental } \\
\text { para produzir alimentos }\end{array}$ & $\begin{array}{l}\text { Danos ao meio ambiente são } \\
\text { passíveis ações na justiça, } \\
\text { que resultam em } \\
\text { compensações ecológica e } \\
\text { econômica, de acordo com o } \\
\text { Código Florestal do Brasil. }\end{array}$ & $\begin{array}{l}\text { Associe o plantio de } \\
\text { reflorestamento com a produção de } \\
\text { alimentos, preferencialmente } \\
\text { espécies nativas alimentícias de } \\
\text { diferentes extratos. }\end{array}$ \\
\hline $\begin{array}{l}\text { Superquadra como } \\
\text { unidade produtiva (Re- } \\
\text { Ação) }\end{array}$ & $\begin{array}{l}\text { Superquadras possuem } \\
\text { amplos espaços vazios entre } \\
\text { prédios que normalmente são } \\
\text { planejados, mas não levam } \\
\text { em conta a produção de } \\
\text { alimentos e suas escalas. }\end{array}$ & $\begin{array}{l}\text { Projete jardins agroflorestais nas } \\
\text { áreas verdes destinadas ao } \\
\text { paisagismo nas superquadras, } \\
\text { próximo às escolas e blocos } \\
\text { residenciais. Use composto e água } \\
\text { coletada pelos edifícios. }\end{array}$ \\
\hline
\end{tabular}


As ações do Governo de Brasília ainda estão concentradas no racionamento de água e uso consciente da água como verificar se há vazamentos de água nos encanamentos de água ou torneiras pingando, utilizar acessórios que economizem água, fechar a torneira durante as atividades rotineiras, economizar água durante o banho, na pia do banheiro, na hora de lavar louças, na lavagem de roupas, carros e áreas externas, escolher vaso sanitário com caixa acoplada que economiza água, esvaziar piscinas na época da seca ou tratar a água sem substituí-la, regar as plantas com regador, não deixar transbordar a água da caixa d'água, captar água limpa da chuva em baldes ou tambores plásticos e reutilizar a água sempre que possível, evitar o descarte de óleo de cozinha na pia.

Não são suficientes para restabelecer o ciclo da água. Assim, esta pesquisa teve como premissa avançar na proposição de ações de planejamento e gestão para recuperar o ciclo da água sob a ótica de uma visão transdisciplinar que trate da situação das águas no Distrito Federal no contexto do Bioma Cerrado e das mudanças climáticas, visando o potencial de novos padrões de uso e ocupação do solo bem como de desenho urbano para melhorar o desempenho do ciclo hidrológico.

\subsection{FAMA - Fórum Alternativo Mundial da Água}

A Assembleia Geral das Nações Unidas (Resolução 64/292) reconheceu explicitamente o direito humano à água e ao saneamento em 2010, enfatizando que ambos são essenciais para a sobrevivência dos seres humanos. $\mathrm{O}$ acesso à água deve ser assegurado para fornecimento a todas $\mathrm{e}$ a todos, independentemente de sua condição social, econômica ou cultural, de gênero ou etnia.

Em contraposição ao $8^{\circ}$ Fórum Mundial da Água, aconteceu em março na Universidade de Brasília o Fórum Alternativo Mundial da Água. De acordo com o site oficial do evento, são objetivos do FAMA ser um evento democrático, para que a informação seja descentralizada e acessível; sensibilizar a sociedade a respeito do problema hídrico por meio de seminários, aulas públicas, oficinas, atividades culturais, etc., denunciar ilegitimidade do FMA; pressionar o governo visando políticas públicas e direito fundamental ao bem; reforçar a luta contra a visão da água como mercadoria e estruturar uma permanência de discussões após o evento por meio de comitês populares.

O projeto do FAMA é uma oportunidade especial de aproximar a sociedade da universidade e de promover a transdisciplinaridade. A universidade produz conhecimento muitas vezes restritos à teoria $\mathrm{e}$ não dispersos para atingir quem necessita aplica-lo. Com o evento, reuniram-se diversos especialistas, pesquisadores, povos indígenas, pessoas de diversas áreas do conhecimento para esclarecer pontos de vistas e trocar experiências, por diferentes meios, variando desde palestras até oficinas culturais, ramificações do assunto, buscando aproximar todas as áreas para uma mobilização mais eficiente a respeito da problemática hídrica.

Os produtos gerados foram manifestos, declarações e cartas que deram voz aos povos indígenas, quilombolas e populações tradicionais. Na Faculdade de Arquitetura e Urbanismo, a organização foi coordenada pela professora Liza Andrade. Algumas dificuldades relacionadas à estrutura levaram ao improviso de espaço, o que desanimou a equipe pelo descaso com a mobilização, mas não impediu que o evento ocorresse. Por outro lado, o fato de o evento ter ocorrido nos ateliês abertos logo na entrada faculdade chamou a atenção das pessoas que estavam nos corredores do Instituto Central de Ciências, colaborando para o sucesso de público do evento. 
As palestras realizadas por vários professores da Universidade de Brasília, com registros em vídeo divulgado no YouTube, reafirmam a intenção de integrar o público externo da universidade. Também foi produzido um cartaz resumo referente às palestras (Figura 3), exposto no local durante o evento e na semana seguinte.

Figura 3. Cartaz com a programação do evento inserido no FAMA proposto pelo Grupo Água e Ambiente Construído (à esquerda) e Poster síntese do Evento ocorrido (à direita).

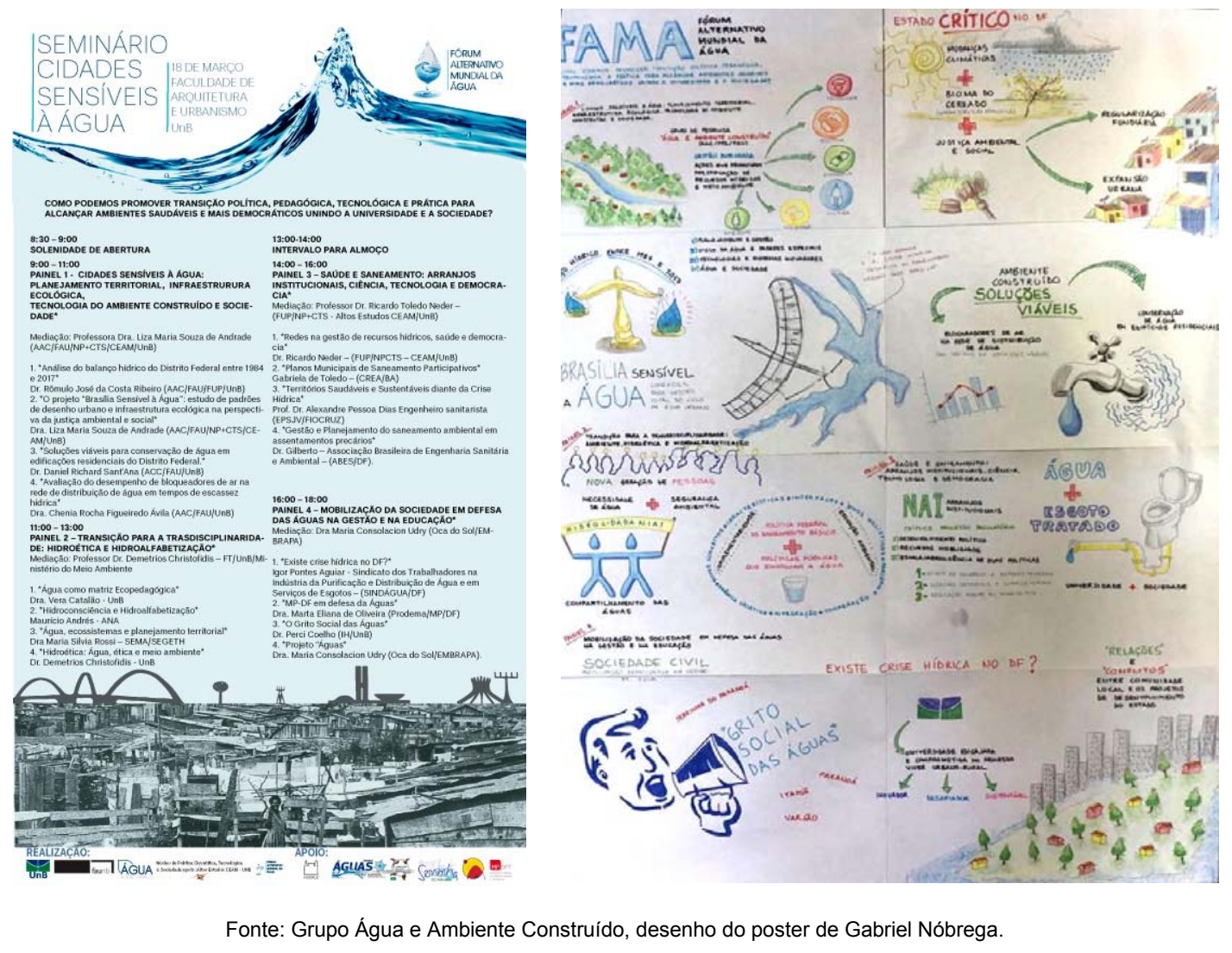

\section{A proposta para a Pedagogia do Ciclo da Água Urbano}

Em contribuição à construção do "Manual pedagógico para o entendimento do ciclo da água na bacia hidrográfica e o engajamento social frente à escassez hídrica no DF", foram estudados vários projetos engajados na causa hídrica com diferentes didáticas, meios e dinâmicas pedagógicas. O fator comum mais relevante entre os projetos apresentados foi a linguagem acessível. Tratar de assuntos técnicos com uma linguagem adequada para a sociedade favorece a promoção dos objetivos, pois facilita a compreensão e aproxima o tema do contexto do receptor.

Outra ferramenta importante observada foi o uso de ilustrações, que também facilitam a compreensão, e agrega ao produto um caráter divertido e informal que estimula o público a acompanhar o assunto.

As figuras 4 usou como base teórica a tabela de padrões especiais de infraestrutura ecológica gerada pelo Pibic de Alessandra Oliveira: "O CICLO DA ÁGUA NO CERRADO: novos padrões urbanos para restabelecer o equilíbrio do trinômio solo-vegetação-atmosfera", que trata da inserção de plantas nativas do cerrado na zona urbana e de pavimentação permeável em zonas residenciais e vias de baixa velocidade, manobras e estacionamentos.

A figura 5 (à esquerda) informa sobre corredores ecológicos e foi embasada pelo Pibic de Bruna Rambo: "CORREDORES ECOLÓGICOS: conexões entre biodiversidade, fluxos de água e uso do solo na Bacia do Lago Paranoá". Na figura 5 (ao centro e à direita) são ideias do trabalho: "Análise da relação da heterogeneidade espacial e os fluxos de água da Bacia Hidrográfica do Lago Paranoá" de 
Luísa Rodrigues, apresentando ao cidadão o telhado verde e benefícios do reuso de água.

Figura 4. Infográficos dos padrões especiais de infraestrutura ecológica.

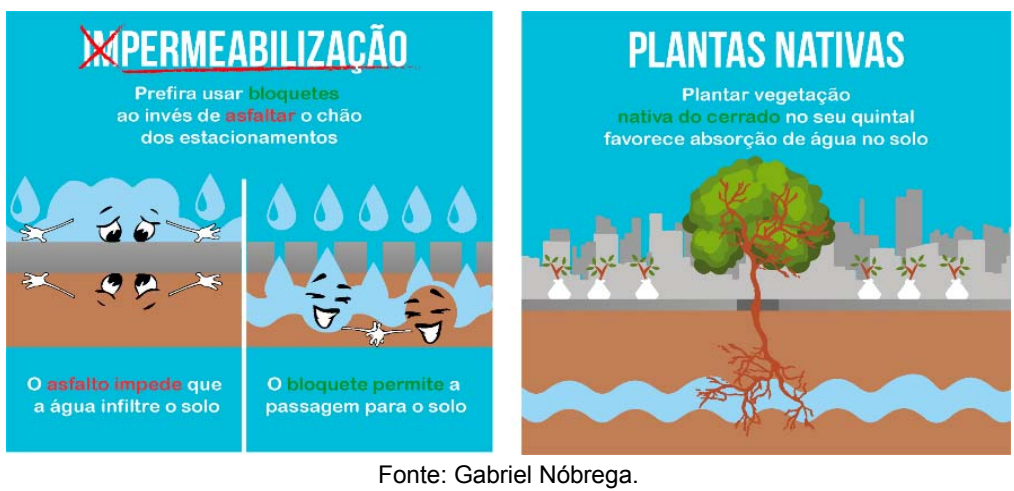

Figura 5. Infográficos sobre corredores ecológicos, telhado verde e reutilização de água.
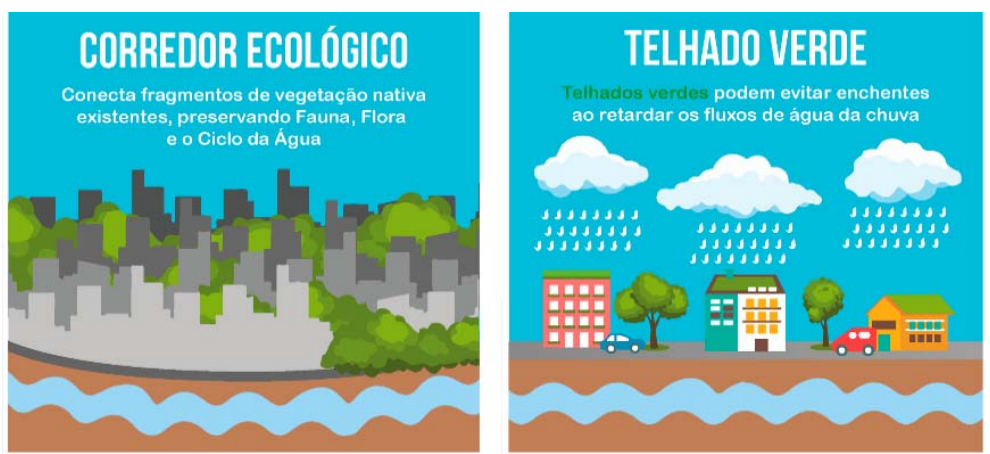

Fonte: Gabriel Nóbrega.

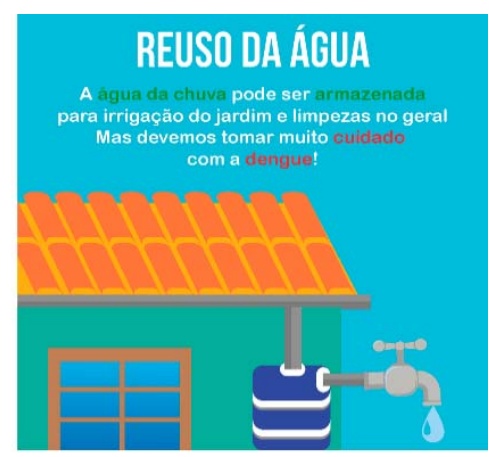

\section{Conclusão}

Os resultados observados levam a conclusão de que a transdisciplinaridade é uma proposta comum entre os projetos, pois ela aproxima as diversas áreas entre si e para a sociedade fora da academia. Também foi notado que as redes sociais são ferramentas eficientes na divulgação de informações, e para a promoção das cidades sensíveis projeta-se o alcance de muitas pessoas por meio delas.

Todos os projetos colaboraram com uma síntese de pedagogias adequadas ao ciclo urbano da água e as imagens propostas ilustram como esse artigo pode contribuir para o "Manual pedagógico do ciclo da água urbano com padrões de infraestrutura ecológica para promover o engajamento social frente à escassez hídrica" inserido no projeto Brasília Sensível à Água, coordenado pela professora Liza Andrade, funcionando como um objeto expositivo, que se adequa desde a parte expositiva na pesquisa-ação, até mesmo produto final de publicação em uma página de redes sociais.

Analisando o projeto australiano, fica evidente que apenas propor mudanças e educar o indivíduo talvez não seja o suficiente, cabe também ao governo acompanhar os processos e amparar possíveis imprevistos. Como um exemplo, ao investir no uso de garrafas de vidro reutilizáveis e educar o cidadão a respeito da quantidade de lixo produzida pela garrafa de plástico descartável, é necessário também criar infraestruturas de filtros para reabastecimento da garrafa. Além de alcançar o objetivo de conscientizar, o ciclo deve ser considerado para não se perder o processo. A mudança deve ser completa e sempre analisada novamente, soluções parciais e imediatas podem agravar ainda mais a situação.

É necessária uma mudança de paradigma em relação à maneira pela qual construímos nossas cidades, uma nova visão multidimensional sistêmica e transdisciplinar, que possibilite uma interface entre ciências naturais, ciências da saúde e das ciências sociais e humanas no espaço urbano. Para 
conseguir alcançar tais metas, técnicos e planejadores da área de recursos hídricos e saneamento, e agências governamentais precisarão integrar as política territoriais às políticas setoriais de desenvolvimento com novos arranjos institucionais e incluir efetivamente as comunidades na gestão compartilhada da água.

\section{Referências}

ÁGUA SUA LINDA. Disponível em: https://www.facebook.com/aguasualinda/ Acesso em 24 de abril de 2019.

ALIANÇA PELA ÁGUA. Disponível em: https://www.aliancapelaagua.com.br/ Acesso em 24 de abril de 2019.

ALEXANDER, C.; ISHIKAWA S.; Murray, S.; JACOBSON, M.; FIKSDAHL-KING, I.; ANGEL, S..1977. A Pattern Language. New York: Oxford University Press.

ANDRADE, L. M. S; BLUMENSCHEIN, Raquel Naves. Cidades sensíveis à água: cidades verdes ou cidades compactas, eis a questão? Paranoá Cadernos de Arquitetura e Urbanismo, PPG-FAU. n.10, p. 59-76, 2013.

ANDRADE, Liza Maria Souza de. Conexão dos Padrões Espaciais dos Ecossistemas Urbanos: a construção de um método com enfoque transdisciplinar para o processo de desenho urbano sensível à água no nível da comunidade e o no nível da paisagem. 2014. Tese (Doutorado) - Faculdade de Arquitetura e Urbanismo, Universidade de Brasília, Brasília.

ANDRADE, Liza Maria Souza de; LACERDA, Guilherme; OLIVEIRA, Alessandra; OLIVEIRA, Adriane; CAMARGO, Pedro; DANTAS, André. Brasília Sensível à Água. In: Encontro da Associação Nacional de Pesquisa e Pós-Graduação em Arquitetura e Urbanismo. Anais... Porto Alegre: 2016.

ANDRADE, Liza Maria Souza de; LACERDA, Guilherme; OLIVEIRA, Alessandra; OLIVEIRA, Adriane; CAMARGO, Pedro; DANTAS, André. Brasília Sensível à Água: a situação crítica das águas no DF em relação ao ciclo da água urbano e à demanda por infraestrutura ecológica. In: SINGEURB 2017, São Carlos, 2017.

BERGER, Jonah. Contágio. Porque as coisas pegam. Tradução de Lúcia Brito. Rio de Janeiro: LeYa, 2014.

CATALÃO, Vera Lessa. Água como matriz ecopedagógica: um projeto a muitas mãos. 1 ed. Brasília: [s.n.], 2006.

FAMA. FÓRUM ALTERNATIVO MUNDIAL DA ÁGUA. Disponível em: http://fama2018.org/ Acesso 24 de abril de 2019.

FAMA. CIDADES SENSÍVEIS À ÁGUA - Como podemos promover a transição política, pedagógica, tecnológica e prática para alcançar ambientes saudáveis e mais democráticos unindo a universidade $\mathbf{e}$ a sociedade? Canal do Youtube. Disponível em: https://www.youtube.com/watch?v=FpbBZujl0jI\&list=PLRwxmrfH2zU4I1h4QjaZIXX4nmL6WGIW7\&inde $\underline{x=3 \% 3 E+A c e s s o+e m \% 3 A+j u l h o+2018}$. Acesso em 24 de abril de 2019.

GEHL, Jan. Cidades para Pessoas. São Paulo: Perspectiva, 2013.

HERZOG, C. P. Cidades para todos: (re)aprendendo a conviver com a natureza. 1 ed. Rio de Janeiro: Mauad X Inverde, 2013. 312p.

HUERGO, Maria Carolina Cherchiglia. Diretrizes para inserção de práticas sustentáveis na melhoria da qualidade ambiental dos centros urbanos - Water Sensitive Urban Design: estudo 
de caso no município de Guaratuba. 2018. Disponível em: https://www.uninter.com/cadernosuninter/index.php/gestao-publica/article/view/555 Acesso em 24 de abril de 2019.

OLIVEIRA, Alessandra Adriane Barbosa. O CICLO DA ÁGUA NO CERRADO: novos padrões urbanos para reestabelecer o equilíbrio do trinômio solo- vegetação- atmosfera. In: $22^{\circ}$ Congresso de Iniciação Científica da UnB e 13 Congresso de Iniciação Científica do DF. 2016. Brasília, Universidade de Brasília.

RAMBO, Bruna Raissa Mangoni. CORREDORES ECOLÓGICOS: conexões entre biodiversidade, fluxos de água e uso do solo na Bacia do Lago Paranoá. In: $23^{\circ}$ Congresso de Iniciação Científica da UnB e $14^{\circ}$ Congresso de Iniciação Científica do DF. 2017. Brasília, Universidade de Brasília.

RIBEIRO, Maurício Andrés. Hidro-Alfabetização. Disponível em https://www.docelimao.com.br/site/debem-com-o-planeta/agricultor-e-consumidor-conscientes/2173-hidro-alfabetizacao-de-todos.html.

Acesso em 24 de abril de 2019.

RODRIGUES, Luísa Barbosa. Análise da relação da heterogeneidade espacial e os fluxos de água da Bacia Hidrográfica do Lago Paranoá. In: $23^{\circ}$ Congresso de Iniciação Científica da UnB e $14^{\circ}$ Congresso de Iniciação Científica do DF. 2017. Brasília, Universidade de Brasília.

WSUD. City of Melbourne WSUD Guidelines. Applying the Model WSUD Guidelines. An Initiative of the Inner Melbourne Action Plan. Melbourne, 2008.

WSUD. Wong T.H.F., Allen R., Brown R.R., Deletić A., Gangadharan L., Gernjak W., Jakob C., Johnstone P., Reeder M., Tapper N., Vietz, G. and Walsh C.J. Blueprint2013 - Stormwater Management in a Water Sensitive City. Melbourne, Australia: Cooperative Research Centre for Water Sensitive Cities, 2013. 